\title{
CD40 Measurement
}

National Cancer Institute

\section{Source}

National Cancer Institute. CD40 Measurement. NCI Thesaurus. Code C82006.

The determination of the amount of CD40 present in a sample. 